\title{
A IMPUTABILIDADE PENAL E OS EFEITOS DO ESTATUTO DA PESSOA COM DEFICIÊNCIA: UMA ANALISE HERMENÊUTICA DAS INCONGRUÊNCIAS
}

\author{
Lucas Helano Rocha Magalhães ${ }^{1}$ \\ Renata Albuquerque Lima ${ }^{2}$
}

\section{RESUMO}

As alterações no Direito brasileiro decorrentes da Lei 13.146/15, o Estatuto da Pessoa com Deficiência, tiveram como objetivo consolidar os direitos civis dos portadores de deficiência. Entretanto, por omissão legislativa somente foram realizadas alterações quanto à capacidade civil ignorando completamente os reflexos em outros campos do Direito. Desta forma, surgiram várias antinomias, em especial no direito penal, quanto à capacidade e a imputabilidade dos portadores de deficiências. Assim, surge a necessidade de realização de uma análise hermenêutica, neste artigo realizado por meio do método interpretativista de Dworkin, com o objetivo de delinear possíveis soluções para as antinomias surgidas no direito criminal. A pesquisa será de natureza bibliográfica com leitura especializada da doutrina.

Palavras-chave: Estatuto da Pessoa com Deficiência; Capacidade; Imputabilidade; Antinomia; Hermenêutica

\section{CRIMINAL IMPUTABILITY AND THE EFFECTS OF THE DISABILITY STATUTE: A HERMENEUTICAL ANALYSIS OF INCONGRUITIES}

\begin{abstract}
The changes in Brazilian law deriving from Law 13,146 / 15, the Disabled Persons Statute, aimed at consolidating the civil rights of persons with disabilities. However, because of a legislative omission changes were made only regarding the civilian capacity completely ignoring the reflexes in other fields of Law. In this way, several antinomies appeared, especially in criminal law, regarding the capacity and imputability of the disabled. Thus, the need arises to perform a hermeneutical analysis, in this article carried out through the interpretive method of Dworkin, with the objective of outlining possible solutions to the antinomies arising in criminal law. The research will be of bibliographic nature with specialized reading of the doctrine.

\footnotetext{
${ }^{1}$ Graduado em Direito pela Universidade Federal do Ceará. Mestrando em Direito no Centro Universitário Christus.

2 Pos-doutora em Direito pela Universidade Federal de Santa Catarina (UFSC). Doutora em Direito pela Universidade de Fortaleza (UNIFOR). Graduada e Mestre em Direito pela Universidade Federal do Ceará (UFC).
}

Revista de Direito Penal, Processo Penal e Constituição | e-ISSN: 2526-0200 | Maranhão | v. 3 | n. 2 | p. 108 - 125 | Jul/Dez. 2017. 
Keywords:Statute of the Person with Disabilities; Capacity; Imputability; Antinomy; Hermeneutics

\section{INTRODUÇÃO}

Muitas alterações legislativas são realizadas com um foco específico, este claramente foi o caso do Estatuto da Pessoa com Deficiência (Lei 13.146/15), o texto da lei veio como forma de consolidar os direitos, em especial os direitos fundamentais de primeira dimensão, ou seja, os direitos da liberdade, os primeiros a constarem do instrumento normativo constitucional, a saber, os direitos civis e políticos (BONAVIDES, 2004), a um grupo que foi historicamente privado deles.

Neste sentido, recortou-se a situação especifica do portador de deficiências mentais, tratado desde as origens do Direito brasileiro como cidadão de segunda classe. Desde as Ordenações Filipinas até o Código Civil de 2002, os portadores estiveram sob a rubrica de incapazes, com grande prejuízo à sua autonomia e muitas vezes à sua dignidade (REQUIÃO, 2015). Neste sentido, deve-se reconhecer a profunda evolução trazida pelo Estatuto, uma vez que afasta o automatismo da relação entre a doença e a incapacidade.

Esta mudança é providencial à luz da medicina moderna, uma vez que a Associação Americana de Psiquiatria mantém o Manual para Diagnóstico e Estatístico dos Transtornos Mentais que lista os principais transtornos psiquiátricos conhecidos. O referido manual engloba doenças que vão de síndromes de ansiedade, de tratamento relativamente simples, até quadros graves que levam a completa inaptidão para interagir com o mundo. Desta forma, mantida a redação original, do Código Civil poder-se-ia afastar a capacidade de quase todos.

A própria noção de capacidade implica na possibilidade de ser agente passivo e ativo em obrigações e direitos, devendo tanto mais se estabelecem ligações comuns de natureza objetiva ou transpessoal tendentes a garantir a livre coexistência das iniciativas privadas(REALE, 2002). Portanto, ao reconhecer a autonomia e capacidade daqueles que possuem transtornos, é conseqüência lógica que estes passem a se submeter também aos deveres contratuais e legais como meio de estabilização social. Ora, se existe a possibilidade de pactuar contratos, naturalmente, passa a existir a possibilidade de uma execução forçosa no caso de descumprimento. 
Entretanto, por opção legislativa, as alterações se restringiram ao Direito Civil, o que cria uma incongruência sistêmica incabível no Direito: se o indivíduo tem plena capacidade para os atos da vida civil, ou seja, tem capacidade de tomar decisões complexas e compreender suas conseqüências, não se pode dizer que não teria esta capacidade para outros campos da vida social.

Essa conclusão trará profundas modificações na forma como enxergamos nas outras áreas do Direito, que não sofreram alteração legislativa, a questão da capacidade. Em campos como o Direito Trabalhista, como nas cotas mínimas de contratação; o Direito Previdenciário, na concessão de benefícios de prestação continuada e, o ponto central deste trabalho, o Direito Penal, na análise de imputabilidade.

Para suprir essas incongruências surgidas da lacuna legislativa, será preciso utilizar-se da hermenêutica para o preenchimento destes espaços e encontrar as repostas adequadas para solução deste problema.

Para este fim, o presente trabalho foi dividio em cinco pontos, o primeiro deles trata das características da imputabilidade no sistema penal brasileiro, demonstrando sua evolução ao longo da legislação brasileira. Em seguida busca-se analisar as alterações trazidas pelo Estatuto da pessoa com deficiência e dos decretos que o precederam.

Assim, prosseguir-se-á analisando os possíveis impactos do Estatuto, com foco nas alterações na capacidade, na imputabilidade criminal. Por fim, será analisada, por meio da Teoria Interpretativista de Dworkin, qual a melhor solução diante das possibilidades apresentadas.

Desta forma, concluiu-se que o Estatuto trouxe uma evolução disruptiva que quebrou a cadeia lógica, e moral, que vinha sendo construída, sendo sua aplicação vinculativa para que se mantenha a integridade sistêmica do Direito brasileiro.

\section{A evolução da imputabilidade no direito penal brasileiro}

A imputabilidade no Direito penal passa por duas esferas principais, a primeira delas cronológica e a segunda derivada diretamente da capacidade de compreensão da natureza e das conseqüências das condutas. No direito pátrio, existem marcos históricos fundamentais que precisam ser discutidos destacando-se as Ordenações Filipinas, o Código 
Penal Imperial, o Código Penal Republicano e o atual Código Penal. Desta forma, se faz necessária uma análise do instituto durante a evolução do Direito aplicado no território nacional.

Inicialmente, as Ordenações Filipinas traziam o conceito de imputabilidade em dois paralelos, o primeiro vinculado diretamente ao critério biológico e cronológico, determinavam a vedação à pena de morte aos menores de 17 anos, e, ainda, permitindo uma redução de pena para os réus que fossem menores de 20 anos.

No direito pátrio independente, o Código Penal do Império adotou o que pode ser chamado de sistema do discernimento, com nítida inspiração no Código Penal Francês, determinando a maioridade penal absoluta a partir dos 14 (quatorze) anos, entretanto os mais jovens poderiam ter a inimputabilidade afastada, desde que restasse comprovada incapacidade de discernimento destes, quanto às ações praticadas.

Este sistema trazia uma evolução com a previsão de um tratamento diferenciado aos inimputáveis, aqueles com “qualquer gênero de loucura”, que eram conduzidos às "casas da loucura” ou, ainda, permitindo que ficassem sob a guarda da família, que passaria a ser responsável pela sua guarda, ademais ainda não eram “titulados” como criminosos. Entretanto, a identificação desta "loucura” derivava diretamente da interpretação íntima do juiz.

Posteriormente, com a promulgação do Código Penal Republicano ocorreu uma reforma da análise da imputabilidade, em um sistema que mesclava os critérios, cronológicos e do discernimento, para definir a imputabilidade penal do individuo. A nova estrutura dividia a imputabilidade em categorias distintas: aqueles com 09 (nove) anos de idade incompletos, eram considerados absolutamente inimputáveis; os menores de 14 (quatorze) anos estariam submetidos à análise do discernimento e os maiores de 14 (quatorze) seriam considerados capazes de discernimento de seus atos.

Destes últimos, era ainda necessária a análise de sua higidez mental, caso representassem perigo à sociedade deveriam ser internados compulsoriamente. Entretanto, já se vislumbrava uma evolução quanto à delimitação daqueles que seriam incluídos neste rol, uma vez que era obrigatório ao juiz identificar o risco social e o tipo de doença do réu.

Posteriormente, em reforma promovida em 1932, foi construída a divisão completa do tratamento dado aos inimputáveis e os “doentes mentais” que deveriam ser conduzidos para hospitais próprios para seu tratamento. 
Por fim, o Código Penal de 1940, em vigor até hoje, adotou o critério puramente biológico, para maioridade penal, impondo que seriam imputáveis as pessoas a partir dos 18 (dezoito) anos. Ademais, trouxe a ressalva à responsabilidade "É isento de pena o agente que, por doença mental ou desenvolvimento mental incompleto ou retardado”, mas trazendo como evolução a medida de segurança. Neste novo período, a medida se fundamentava na irresponsabilidade, ou inimputabilidade, do réu, sendo a medida de segurança um meio de proteger a sociedade e, mais ainda, de garantir um tratamento completo e digno ao réu. Sob este aspecto, deve-se frisar que a internação tornou-se compulsória, dispensando a análise do juiz uma vez que inimputabilidade seria presumida pela lei.

Desta forma, fica claro que de acordo com a evolução do direito penal sempre houve uma tendência ao aumento das proteções para aqueles que tem algum tipo de deficiência mental. Entretanto, a lei Brasileira de Inclusão da Pessoa com Deficiência (13.146/15) trouxe uma quebra de paradigma quanto ao modo como se interpreta as deficiências, em especial as mentais, dentro do direito brasileiro.

\section{As alterações trazidas pela lei $13.146 / 15$}

O Estatuto trouxe importantes modificações ao paradigma jurídico que existia sobre aqueles que possuem algum tipo de deficiência mental. Ele surge como uma clara evolução dos Decretos 3.298/99 (Política Nacional para a Integração da Pessoa Portadora de Deficiência), que traz em linhas gerais o primeiro regramento que trata diretamente dos direitos das pessoas com deficiência no ordenamento brasileiro, e 6.949/09 (Convenção Internacional sobre os Direitos das Pessoas com Deficiência), que constitui obrigações ao Estado quanto a políticas de proteção e ações afirmativas. No ano de 2015, por sua vez, foi promulgado o Estatuto, que traz as mudanças que são o cerne deste estudo.

Merece destaque especial o Decreto de 1999 por trazer alguns conceitos que serão basilares para construção da estrutura de proteção das pessoas com deficiência. Inicialmente, traz-se a definição de deficiência propriamente dita que é conceituada como "toda perda ou anormalidade de uma estrutura ou função psicológica, fisiológica ou anatômica que gere incapacidade para o desempenho de atividade”; o conceito de deficiência permanente "aquela que ocorreu ou se estabilizou durante um período de tempo suficiente para não permitir 
recuperação ou ter probabilidade de que se altere, apesar de novos tratamentos” e incapacidade "uma redução efetiva e acentuada da capacidade de integração social, com necessidade de equipamentos, adaptações, meios ou recursos especiais para que a pessoa portadora de deficiência possa receber ou transmitir informações necessárias ao seu bem-estar pessoal e ao desempenho de função ou atividade a ser exercida”.

Ainda traz outra definição importantíssima para a análise, a de deficiência mental:“funcionamento intelectual significativamente inferior à média” e "limitações associadas a duas ou mais áreas de habilidades adaptativas”, para tanto exige-se que estas limitações estejam associadas à pelo menos duas das seguintes áreas: comunicação; cuidado pessoal; habilidades sociais; utilização dos recursos da comunidade; saúde e segurança; habilidades acadêmica; lazer e trabalho.

Além disso, traz as diretrizes da Política Nacional para Integração de Pessoas com Deficiência, estipulando obrigações ao Estado como o estabelecimento de políticas públicas de inclusão, ampliar as alternativas para inserção de deficientes no mercado de trabalho e a garantia de atendimento das suas necessidades.

A Convenção Internacional de 6.949/09 também traz algumas definições, sendo a mais fundamental a de Discriminação por motivo de deficiência "significa qualquer diferenciação, exclusão ou restrição baseada em deficiência”, explicitando que não pode existir o propósito de impedir o reconhecimento, o desfrute ou o exercício, em igualdade de oportunidades com as demais pessoas, de todos os direitos humanos e liberdades fundamentais nos âmbitos político, econômico, social, cultural, civil ou qualquer outro.

Frisa ainda o respeito pela dignidade inerente, a autonomia individual, inclusive a liberdade de fazer as próprias escolhas, e a independência das pessoas. Desta forma, observase uma gradual evolução com o intuito de consolidar os direitos fundamentais dos deficientes

O Estatuto da Pessoa com Deficiência, lei 13.146/15, desenvolve ainda mais o aspecto de proteção aos Direitos Fundamentais, trazendo, em seu artigo $4^{\circ}$ de forma expressa que "toda pessoa com deficiência tem direito à igualdade de oportunidades com as demais pessoas e não sofrerá nenhuma espécie de discriminação”. Trazendo ainda fortes implicações como o destaque de que a deficiência não afeta a plena capacidade civil da pessoa.

Neste sentido, faz-se um destaque especial à inversão paradigmática decorrente da lei que alterou o conceito referente a capacidade civil, até a promulgação do Estatuto, as pessoas com deficiências mentais eram presumidamente incapazes. 
Ocorre que a alteração decorrente da lei realizada no Código Civil em seu artigo $4^{\circ}$ retirou os excepcionais do rol dos relativamente incapazes. Desta forma, o ordenamento jurídico passou por uma inversão de valores: a incapacidade deixa de ser presumida, devendo ser comprovada no caso concreto.

Esta conclusão também é literal, conforme a Convenção, que determina uma avaliação biopsicossocial que deve ser realizada "por uma equipe multiprofissional e interdisciplinar. E mais ainda, ainda que exista uma limitação, a individualidade não pode ser tolhida devendo-se respeitar as suas decisões de âmbito pessoal, como a liberdade matrimonial e sexual.

No âmbito do direito civil, são mais claros os efeitos do Estatuto, uma vez que foram tratados de forma direta. Por exemplo, verifica-se que o instituto da curatela foi afastado, sendo cabível somente quando houver a incapacidade de manifestação. Em sua substituição o Estatuto trouxe o instituto da Tomada de Decisão Assistida, no qual a decisão final cabe ao assistido, que é apoiado com informações e auxílio de seus apoiadores. Entretanto, a assistência limita-se ao aspecto patrimonial, não podendo estender-se à outros aspectos da vida do assistido.

Entretanto, em outros campos do direito, em especial no direito penal, deve-se questionar os efeitos jurídicos do novo paradigma de capacidade.

\section{Os possíveis efeitos no Direito Penal}

Inicialmente, é necessário que analise-se que os efeitos da lei têm aplicações tanto quando a pessoa portadora de deficiência mental encontra-se no pólo passivo quando se encontra no pólo ativo da relação penal. Entretanto, o Estatuto não trouxe inovações ao Código Penal, que permaneceu adstrito à presunção de incapacidade, como veremos adiante essa leniência do legislador pode trazer graves conseqüências dentro da seara criminal.

Os efeitos no pólo passivo provavelmente serão aqueles que implicarão em um debate mais aprofundado em virtude de suas aplicações práticas. Em decorrência do decreto de 1999, ao longo dos anos foram incluídos diversos adendos à tipos penais que visavam uma maior proteção dos portadores de deficiência, em especial, situações que implicavam no aumento de pena. Nesta perspectiva, não parece existir campo hermenêutico para discussão, uma vez que o Estatuto traz de maneira expressa que “a pessoa com deficiência será protegida 
de toda forma de negligência, discriminação, exploração, violência, tortura, crueldade, opressão e tratamento desumano ou degradante”.

Por outro lado, existe uma situação absolutamente limítrofe, que ainda não recebeu tratamento pelos tribunais é a do estupro de vulnerável. Conforme aventado anteriormente, o Estatuto traz de maneira expressa que mesmo a pessoa com deficiência tem completa liberdade para sua autodeterminação inclusive sob aspectos sexuais.

Desta forma, embora exista dissidência doutrinária que considera inexistir o problema, alegando que é necessário apurar se a enfermidade ou a deficiência mental de que padeça alguém ocasiona a falta de discernimento (SANCHES, 2016), contudo não parece razoável assumir que a alteração ocorrida em 2009, que afastou a violência presumida seja suficiente para solucionar este problema em razão da sofisticação do tipo penal ${ }^{\mathrm{i}}$.

A sofisticação trazida pela lei12.015/09 já traz uma importante evolução, uma vez que já limita os casos em que os atos sexuais praticados por pessoas com deficiências mentais não são obrigatoriamente tratados como crime. Neste ponto, percebe-se um alinhamento com o posicionamento trazido pelo Estatuto que reconhece a Direito Fundamental à liberdade sexual dos portadores de deficiência. Contudo, na época da promulgação desta alteração, portanto anterior ao estatuto, a incapacidade era presumida, ou seja, a defesa do réu deveria comprovar a capacidade da vítima, vez que todo o sistema jurídico passava por este posicionamento.

Com a inversão decorrente do Estatuto, temos uma nova situação fática: todos são presumidamente capazes, inclusive sexualmente, até que exista uma comprovação do contrário e ainda mais grave, segundo a Convenção Internacional, somente por uma equipe multidisciplinar. Desta forma, cabe o questionamento em uma situação fática seria o homem médio capaz de identificar o discernimento para prática do ato sexual?

Neste sentido, parece claro que a punibilidade poderia ser absolutamente afastada, por exemplo, quando ocorresse erro de tipo ${ }^{i i}$ : o discernimento, ou sua ausência, é um elemento fundamental do crime, desta forma trata-se de elemento constitutivo do crime, logo o erro sobre sua existência afastaria a forma dolosa, como no caso não existe previsão de modalidade culposa seria afastada a punibilidade.

Desta forma, encontramos uma incongruência sistêmica por um lado afirma-se que o crime por sua natureza é hediondo, mais grave do que os outros crimes tipificados no ordenamento, em razão da incapacidade da vítima se defender e, por outro, que, embora tenha 
essas características, no campo fático não é possível discernir esta incapacidade de maneira clara.

Demonstrada a dificuldade trazida ao sistema quando se coloca o portador de deficiência mental como vítima de crimes, passamos para uma análise ainda mais complexa. Como deve ser tratado o réu após a alteração legislativa?

O Código Penal, de 1940iiii, traz uma clara definição à inimputabilidade daquele considerado "inteiramente incapaz de entender o caráter ilícito do fato ou de determinar-se de acordo com esse entendimento", em virtude de ser "isento de pena o agente que, por doença mental ou desenvolvimento mental incompleto ou retardado”. Ou seja, segundo um critério tradicional, que o Código rejeitou, haveria que distinguir entre responsabilidade e imputabilidade, significando esta a capacidade de direito penal ou abstrata condição psíquica da punibilidade, enquanto aquela designaria a obrigação de responder penalmente in concreto ou de sofrer a pena por um fato determinado, pressuposta a imputabilidade. A distinção é bizantina e inútil. Responsabilidade e imputabilidade representam conceitos que de tal modo se entrosam, que são equivalentes, podendo, com idêntico sentido, ser consideradas in abstracto ou in concreto, a priori ou a posteriori. (HUNGRIA, 1958)

A visão proposta por Nelson Hungria, em que pese sua importante influencia em todos os estudiosos posteriores, tem correlação direta com a interpretação à época da edição do Código Penal. Desta forma, faz-se necessário também analisar como alguns dos principais estudiosos do tema na atualidade se manifestam. Neste esteio, podemos encontrar posições pós-constituição como podemos alterar algumas definições frisando-se algumas falhas do código podendo, por exemplo, destacar a imprecisão terminológica utilizada para definir a doença mental "embora vaga e sem rigor científico, a expressão abrange todas as moléstias que causam alterações mórbidas à saúde mental” (MIRABETE, 2006) que pode ainda ser complementado pela definição de Sanzo Brodt (1996):

“A imputabilidade é constituída por dois elementos: um intelectual (capacidade de entender o caráter ilícito do fato), outro volitivo (capacidade de determinar-se de acordo com esse entendimento). O primeiro é a capacidade (genérica) de compreender as proibições ou determinações jurídicas. Bettiol diz que o agente deve poder 'prever as repercussões que a própria ação poderá acarretar no mundo social', deve ter, pois, 'a percepção do significado ético-social do próprio agir'. O segundo, a 'capacidade de 
dirigir a conduta de acordo com o entendimento ético- jurídico. Conforme Bettiol, é preciso que o agente tenha condições de avaliar o valor do motivo que o impele à ação e, do outro lado, o valor inibitório da ameaça penal”.

Esta definição dialogava de maneira clara e sistêmica com os conceitos estabelecidos no Direito Civil, Constitucional e mesmo com a Convenção Internacional sobre os Direitos das Pessoas com Deficiência. Ocorre, que o Estatuto trouxe ao Direito brasileiro uma nova perspectiva de capacidade dos deficientes mentais, até então eles eram presumidamente incapazes, com a mudança legislativa passaram a ser presumidamente capazes inclusive de atos complexos, como casamento, união estável e adoção, devendo ser somente assistidos sobre questões patrimoniais. Assim, parece dissonante que este mesmo indivíduo seja considerado incapaz de compreender as conseqüências de suas atitudes quando estas se referem a ilícitos.

Além da imputabilidade propriamente dita, deve-se discutir também a problemática da pena que deve ser culminada aos réus que se encontram nesta categoria incluir na discussão a questão que diz respeito à medida de segurança que tem como objetivo primário a recuperação clínica do infrator e sua reinserção social.

A medida é definida como uma “absolvição imprópria”, vez que não possui a característica de sanção penal propriamente dita. Ela deve ser determinada não pela análise de culpabilidade, mas por meio de uma análise da periculosidade do réu. Neste ponto, serve como meio preventivo com a intenção de proteção do réu. Em virtude desta característica não existe prazo determinado para o cumprimento da medida, ela prosseguirá até o restabelecimento do infrator.

Com o advento do Estatuto surgem três questionamentos claros: A) considerando que a capacidade como pressuposto natural, é razoável permanecer utilizando a distinção de penas? B) diante do mesmo pressuposto, é razoável a existência de uma medida de segurança sem prazo definido? C) É possível cumular a obrigação de indenizar quando aplicada medida de segurança?

Tratam-se, as situações, portanto, de uma situação com fortes argumentos em ambos os sentidos. Desta forma, é imprescindível uma análise hermenêutica precisa para que se apresente uma saída para o problema.

\section{A Teoria Interpretativista de Dworkin e o princípio da integradade}


Os questionamentos apresentados anteriormente ainda não tiveram uma análise aprofundada pela jurisprudência e, tampouco, pela doutrina. Desta forma, faz-se necessário uma análise cuidadosa sobre o tema. Em virtude da complexidade do tema e de seu forte conteúdo moral, parece ser adequada a escolha pelo método interpretativista defendido por Ronald Dworkin (1999).

A teoria interpretativa propõe que as divergências são causadas diretamente pelos fortes argumentos de que uma interpretação diversa seria mais coerente com os princípios e virtudes socialmente eleitos, desta forma rejeita a ideia de que a textura aberta da norma é a causadora destas divergências.

Desta forma, a norma só será confusa se "houver, pelo menos, uma dúvida sobre se a lei representaria um melhor desempenho da função legislativa se interpretada de um modo, e não de outro” (DWORKIN, 1999). Ou seja, a obscuridade de uma norma não é uma característica intrínseca, mas que surge pela força argumentativa de duas posições distintas. Neste sentido, entende as interpretações de norma como criativas, sendo construtivas na medida em que se preocupam essencialmente com o propósito, fundamentalmente o do intérprete, não o do autor (DWORKIN, 1999).

Dessa forma, a interpretação construtiva impõe um propósito a um objeto ou prática a fim de torná-lo o melhor possível. Sem que se construa uma decisão de maneira arbitrária, vez que o contexto geral traz amarras inquebráveis limitando as interpretações possíveis. A teoria define que o método interpretavista parte de dois pressupostos: o de que a prática não apenas existe, mas tem uma finalidade e que as regras da prática social devem ser compreendidas e aplicadas segundo essa finalidade.

Ou seja, a interpretação repercute na prática, alterando sua forma, e a nova forma incentiva uma nova interpretação. Assim, a prática passa por uma dramática transformação, embora cada etapa do processo seja uma interpretação do que foi conquistado pela etapa imediatamente anterior (DWORKIN, 1999).

Para tanto, vale-se de um método bem estruturado que passa por algumas etapas definidas a primeira dela é pré- interpretativa quando são identificadas as regras e os padrões que se consideram fornecer o conteúdo experimental da prática (DWORKIN, 1999). Esta primeira etapa tem como objetivo definir qual a delimitação da norma a ser interpretada, sendo necessário que essas convicções sejam compartilhadas pelos membros da comunidade. 
Em seguida, já na etapa interpretativa, busca-se identificar a “justificativa geral” para a norma, o que permitirá identificar qual o significado é adequado. Novamente, esses significados precisam ser razoavelmente compartilhados pela comunidade.

Por fim, na etapa pós-interpretativa, será indicado entre os significados considerados adequados, aquele que mostra a norma sob sua melhor luz. Entretanto, diferentemente das etapas anteriores, essas convicções não precisam ser tão compartilhadas pela comunidade quanto à noção do intérprete acerca dos limites da pré-interpretação, ou mesmo quanto a suas convicções sobre o devido grau de adequação (DWORKIN, 1999).

Em sua obra, destaca ainda, a importância da integridade, pilar fundamental deste artigo, definindo sua importância ao destacar o direito como completude supõe que as pessoas têm direito a uma extensão coerente, e fundada em princípios, das decisões políticas do passado, mesmo quando os juízes divergem profundamente sobre seu significado (DWORKIN, 1999).

Para tanto, afasta outras duas concepções antagônicas do Direito: o convencionalismo e o pragmatismo jurídico. A primeira concepção estabelece que existe somente os direitos expressamente convencionados em textos normativos, latu sensu, englobando os legais ou jurisprudenciais. Estes textos normativos devem servir como base para as decisões, sendo que, em caso de esgotamento da força das convenções pretéritas, a deliberação deverá ser tomada discricionariamente, nos moldes juspositivista clássicos. O segundo por sua vez, estabelece que não existem prerrogativas fixadas no passado, pois o que efetivamente importa é que as decisões sejam tomadas com o objetivo de edificar o melhor futuro para comunidade, de forma flexível, nos moldes das teorias econômicas do Direito.

Para afastar as teorias do convencionalismo e do pragmatismo jurídico em preponderância da integridade argumentava contra a primeira com base na ampla discricionariedade nas decisões. Quanto à segunda é rejeitada em virtude da negação dos fundamentos principiológicos das Decisões ao delegar aos juízes o poder de adotar soluções que atendam a políticas (metas ou objetivos), mesmo em detrimento de Princípios Jurídicos caros à comunidade

Desta forma, faz-se necessário submeter as questões levantadas ao sistema analítico proposto por Dworkin para verificar como devemos interpretar e aplicar as normas de acordo com os princípios que são capazes de apresentar a melhor justificativa sistêmica, embora reconheça a possibilidade de ocorrer uma variação histórica ao longo dos anos. 
Segundo o autor a produção jurisprudencial funciona como um romance em cadeia, no qual os autores atuais precisam se adequar à história que vinha sendo contada.

Uma vez escolhido o método interpretativo, deve-se realizar uma análise detalhada dos problemas expostos.

\section{Análise da imputabilidade por meio da Teoria Interpretativista}

Conforme apresentado anteriormente, com o advento do Estatuto da Pessoa com Deficiência surgiram algumas inconsistências sistêmicas no direito brasileiro. Desta forma, será realizada a análise conforme o método interpretativista, com o intuito de verificar qual deve ser o caminho indicado para solução da antinomia referente à capacidade.

Inicialmente, na fase pré-interpretativa, analisamos a delimitação da norma, existindo duas posições opostas: por um lado o Estatuto prevê plena capacidade por outro a legislação penal, mais antiga, prevê grandes limitações à autonomia. Ambas as normas, embora diametralmente opostas em seus meios, parecem ter como finalidade a proteção dos portadores de algum transtorno mental, um valor moral amplamente compartilhado pelos membros da sociedade.

É neste ponto que surge o desafio hermenêutico, ambas as normas baseiam-se no mesmo princípio e tem a finalidade, contudo, seus meios de efetivação divergem. Desta forma, a delimitação para discussão parece ser clara: deve-se optar pelo meio mais adequado para consolidação da proteção. Deve-se buscá-la por meio de uma constrição no âmbito das liberdades civis ou deve-se antes de tudo assegurar a liberdade e realizar nos casos, após a concretização dos ilícitos, a análise de capacidade?

Na segunda etapa, busca-se identificar a “justificativa geral” para a norma, ambas as normas se justificam pelo tratamento especial que precisa ser dado aos portadores de deficiência mental. O diploma penal busca por meio de penas mais gravosas àqueles que cometem crimes contra os portadores de deficiência e ao mesmo tempo concede benesses aos réus na mesma condição, em ambos os casos o argumento deriva de uma suposta incapacidade. O Estatuto prevê a plena capacidade civil, partindo do pressuposto de que todo indivíduo é capaz, devendo somente após uma perícia multidisciplinar afirma-se o contrário. 
Nesta segunda etapa, da interpretação propriamente dita, permanece a dificuldade apresentada na análise prévia, à justificativa geral das normas tem, além da mesma justificativa moral, o mesmo conteúdo central garantir uma proteção mais elaborada aos portadores de deficiência.

Desta forma, resta ao terceiro tópico, o da adequação, aqui parece residir a solução para o dilema hermenêutico enfrentado. Tendo em vista a lógica proposta por Dworkin, a “narrativa em série”, a resposta óbvia recairia sobre a manutenção do antigo modelo de capacidades. Ocorre que fora do sistema jurídico ocorreu grande evolução na forma como se entende a mente humana e as patologias que a atingem e, por conseqüência, foi necessária uma mudança na postura legislativa.

Assim, tendo delimitado os submeter os questionamentos levantados aos dois parâmetros possíveis e analisar a adequação de suas respostas.

\section{CONCLUSÕES}

O presente trabalho se propôs a analisar os efeitos do Estatuto da Pessoa com Deficiência com especial enfoque no Direito Penal. Desta forma, busca-se responder os questionamentos levantados.

Conforme a análise metodológica anterior faz-se necessário refletir sobre cada um dos questionamentos propostos: A) como deve ser avaliado o estupro de vulnerável, cometido contra deficientes mentais. Seria o homem médio capaz de identificar o discernimento para prática do ato sexual? B) é razoável permanecer utilizando a distinção de penas de acordo com a capacidade? C) diante do mesmo pressuposto, é razoável a existência de uma medida de segurança sem prazo definido? D) É possível cumular a obrigação de indenizar quando aplicada medida de segurança?

Para responder estes questionamentos devemos submetê-los as duas premissas consolidadas anteriormente: 1) A estabelecida pelo Direito Penal, que tende a uma postura paternalista de proteção dos deficientes e 2) A estabelecida pelo Estatuto, que prioriza os direitos civis individuais e a liberdade pessoal.

Para o primeiro questionamento, (A) referente ao estupro de vulnerável, na postura paternalista do Direito Penal (1) é inafastável o crime, uma vez que prioriza-se a proteção, em detrimento das liberdades individuais. 
Por outro lado, (2) a ruptura proposta pelo Estatuto tornaria o tipo penal ultrapassado, por partir de uma premissa de incapacidade da vítima do crime. Em que pese o objetivo de proteção, este, em primeiro momento, não parece ser mais relevante do que garantir direitos civis, liberdade e dignidade. Neste sentido, não é compatível dentro de um mesmo sistema jurídico que se afirme a liberdade sexual e a plena capacidade e ao mesmo tempo obrigar que se pressuponha a incapacidade. Desta forma, a construção do tipo penal implicaria em um permanente erro de tipo daqueles que incorressem no delito e, inexistindo a modalidade culposa, tornar-se-ia um crime de sanção impossível.

Desta forma, a interpretação mais adequada parece ser uma intermediária, que indica que o crime tipificado só poderá ser aplicado em casos específicos nos quais seja absolutamente inescusável o reconhecimento da situação da vítima, por exemplo, quando esta se encontra completamente incapacitada de exprimir sua vontade.

Os outros questionamentos referem-se à imputabilidade penal. A interpretação adequada ao Código Penal (1) traria uma situação muito próxima à atual. Ora, a lei é taxativa, aqueles que possuem doença mental ou desenvolvimento mental incompleto ou retardado são isentos de punibilidade se não pudessem compreender de maneira clara seus atos. Entretanto, esta determinação derivaria somente do livre convencimento motivado do juiz, ainda que auxiliado por peritos. Em contraponto, as definições trazidas pelo Estatuto (2) construiriam uma figura impossível, a de um indivíduo plenamente capaz em suas atividades cotidianas, inclusive capaz de firmar contratos complexos, mas incapaz de compreender regras sociais básicas e por isso isento das implicações penais. Neste sentido, é imperioso que se reconheça que a ampliação de direitos implica também em um incremento de obrigações.

Desta forma, os réus, ainda que possuam algum tipo de doença mental, não podem ser classificados como inimputáveis, em conformidade com o novo entendimento do Estatuto, ainda que não tenham sido realizadas as alterações necessárias no Código Penal, somente admite uma semi-imputabilidade, ou seja, uma redução proporcional da pena, mas nunca uma completa incapacidade de compreender seus atos.

Realizada esta análise sistêmica, busca-se agora responder os outros questionamentos, que derivam diretamente da interpretação da limitação de responsabilidade daqueles que são portadores de doenças mentais. 
A primeira delas refere-se à distinção das penas aplicadas (B), em especial a medida de segurança e as penas privativas de liberdade. Conforme exposto anteriormente, a medida de segurança tem como objetivo reprimir a periculosidade do réu, não necessariamente analisando-se sua culpabilidade, ressaltando-se ainda que não seria necessário o estabelecimento de um prazo para o cumprimento da medida.

Desta forma, a distinção de penas permanece possível, contudo também surge a possibilidade de uma acumulação de penas, ou seja, o cumprimento de medida de segurança, até o restabelecimento do réu, e uma pena restritiva de liberdade após este momento. Logo, é conseqüência lógica desta divisão, a impossibilidade, sob as premissas do Estatuto da Pessoa com Deficiência a manutenção de medidas de segurança sem um prazo pré-estabelecido (C), uma vez que a determinação do estado de saúde necessariamente deverá passar por uma equipe multidisciplinar de forma periódico. Assim, podem ser consideradas as medidas de segurança podem ser detentivas (internação) ou restritivas (tratamento ambulatorial), contudo não existe vinculação entre a pena prevista no tipo penal (reclusão e detenção) e a medida restritiva, que deverá ser adequada pelo juízo de acordo com o caso.

Da mesma maneira, parece ser absolutamente coerente, vez que se admite a cumulação de penas, a responsabilização patrimonial pelos delitos (D). Ou seja, que o réu realize o pagamento compensatório dos danos causados ou mesmo que seja aplicada multa. Essa conclusão é respaldada principalmente pela possibilidade aberta pela tomada de decisão assistida, que permite ao portador de doença que realize todos os atos patrimoniais desde que tenha o suporte para tomar suas decisões com plena ciência das circunstâncias que envolvem o negócio.

Deste modo, deduz-se que com a evolução social e médica no tratamento daqueles que são portadores de algum tipo de doença mental, não era mais compatível com o Estado Democrático de Direito. O novo paradigma trazido pelo Estatuto da Pessoa com Deficiência buscou resguardar os direitos civis e as liberdades dos portadores de deficiência. Desta forma, implementou a proteção a direitos, em especial aqueles relacionados à esfera personalíssima, como maneira de garantir a integração social. Contudo, a ampliação de direitos implica também no aumento das obrigações, contratuais e sociais, no caso do Direito Penal, o afastamento da figura da incapacidade total, ocasiona também o afastamento de algumas proteções jurídicas. 
Conclui-se, com este artigo, então que a evolução do direito, especialmente quando se traz uma ruptura lógica ao sistema anteriormente constituído, encontra uma profunda dificuldade em manter a coerência e a integridade. Essa dificuldade decorre da ausência de rigor teórico e da dificuldade legislativa em analisar os efeitos e desdobramentos dos novos regramentos.

Desta forma, é necessário o restabelecimento da integridade sistêmica do direito por meio de uma análise hermenêutica, desta vez, com o devido rigor teórico e cuidadosa análise dos efeitos jurídicos da interpretação daquela evolução disruptiva. Sendo, portanto, necessário aplicar os novos conceitos trazidos pelo Estatuto no Direito Criminal.

\section{REFERÊNCIAS}

BONAVIDES, Paulo. Curso de direito constitucional. São Paulo: Malheiros, 2004.

DWORKIN, Ronald. M., O Império do Direito. Tradução de Jefferson Luiz Camargo. São Paulo: Martins Fontes, 1999.

HUNGRIA, Nelson. Comentários ao Código Penal: Arts. 11 a 27. 4 ed. Rio de Janeiro: Forense, 1958.

MIRABete, Júlio Fabbrini; Fabbrini, Renato N. Manual de Direito Penal, vol. 1: Parte Geral. 24 ed. São Paulo: Atlas, 2007

PEREIRA, Caio Mario da Silva. Instituições do Direito Civil, 24a edição. Rio de Janeiro: Editora Forense, 2011.

REQUIÃO, Maurício. Autonomias e suas limitações. In: Revista de direito privado, ano 15, vol.60. São Paulo: Revista dos Tribunais, 2014.

SANCHES, Rogério. O crime de estupro de vulnerável e o Estatuto da Pessoa com Deficiência. Disponível em: https://www.cers.com.br/noticias-e-blogs/noticia/o-crime-deestupro-de-vulneravel-e-o-estatuto-da-pessoa-com-deficiencia < Acessado em: 23/06/2017>

Brodt, Luis Augusto Sanzo. Da consciência da ilicitude no direito penal brasileiro. Belo Horizonte: Del Rey, 1996.

\footnotetext{
i Art. 217-A. Ter conjunção carnal ou praticar outro ato libidinoso com menor de 14 (catorze) anos: Pena - reclusão, de 8 (oito) a 15 (quinze) anos.
} 
§ 10 Incorre na mesma pena quem pratica as ações descritas no caput com alguém que, por enfermidade ou deficiência mental, não tem o necessário discernimento para a prática do ato, ou que, por qualquer outra causa, não pode oferecer resistência.

ii Art. 20, caput, CP: O erro sobre elemento constitutivo do tipo legal de crime exclui o dolo, mas permite a punição por crime culposo, se previsto em lei.

iii Art. 26 - É isento de pena o agente que, por doença mental ou desenvolvimento mental incompleto ou retardado, era, ao tempo da ação ou da omissão, inteiramente incapaz de entender o caráter ilícito do fato ou de determinar-se de acordo com esse entendimento.

Parágrafo único - A pena pode ser reduzida de um a dois terços, se o agente, em virtude de perturbação de saúde mental ou por desenvolvimento mental incompleto ou retardado não era inteiramente capaz de entender o caráter ilícito do fato ou de determinar-se de acordo com esse entendimento. 